CLINICAL STUDY

\title{
The influence of body mass index and renin-angiotensin- aldosterone system activity on the relationship between 25-hydroxyvitamin $D$ and adiponectin in Caucasian men
}

\author{
Anand Vaidya $^{1,2}$, John P Forman ${ }^{2,3}$, Patricia C Underwood ${ }^{1,2,4}$, Paul N Hopkins ${ }^{5}$, Gordon H Williams ${ }^{1,2}$, \\ Luminita H Pojoga $^{1,2}$ and Jonathan S Williams ${ }^{1,2}$ \\ ${ }^{1}$ Division of Endocrinology, Diabetes, and Hypertension, Brigham and Women's Hospital, 221 Longwood Avenue, RFB 386, Boston, Massachusetts \\ 02115, USA, ${ }^{2}$ Department of Medicine, Brigham and Women's Hospital and Harvard Medical School, Boston, Massachusetts, USA, ${ }^{3}$ Renal Division and \\ Channing Laboratory, Boston, Massachusetts, USA, ${ }^{4}$ School of Nursing, Boston College, Boston, Massachusetts, USA and ${ }^{5}$ Cardiovascular Genetics, \\ Department of Internal Medicine, University of Utah School of Medicine, Salt Lake City, Utah, USA
}

(Correspondence should be addressed to A Vaidya at Division of Endocrinology, Diabetes, and Hypertension, Brigham and Women's Hospital; Email: avaidya1@partners.org)

\begin{abstract}
Objective: Previous studies have suggested that circulating adiponectin concentrations are associated positively with vitamin D and negatively with body mass index (BMI) but have not accounted for the influence of the renin-angiotensin-aldosterone system (RAAS) in this relationship. This is particularly relevant because increased RAAS activity is associated with obesity and is known to lower adiponectin levels. We evaluated the association between adiponectin and 25-hydroxyvitamin D (25(OH)D) after controlling RAAS activity with dietary sodium equilibration and also evaluated whether this relationship was influenced by BMI.

Design: Cross-sectional study of 115 hypertensive Caucasian men from the Hypertensive Pathotype Consortium.

Methods: To manipulate RAAS activity, all subjects underwent 1 week of high dietary sodium (HS) diet to suppress RAAS and 1 week of low dietary sodium (LS) diet to stimulate RAAS. Linear regression was used to evaluate the association between adiponectin and $25(\mathrm{OH}) \mathrm{D}$, and the effect of BMI on this relationship, in each dietary condition.

Results: Adiponectin was higher on HS, where circulating RAAS activity was low, when compared with LS (HS $=2.9$ versus $\mathrm{LS}=2.4 \mu \mathrm{g} / \mathrm{ml}, P<0.0001)$. $25(\mathrm{OH}) \mathrm{D}$ levels were positively associated with adiponectin, and BMI was a statistically significant effect modifier of the relationship between $25(\mathrm{OH}) \mathrm{D}$ and adiponectin on both diets ( $P$ interaction $<0.01$ between BMI and 25(OH)D).

Conclusions: Higher 25(OH)D concentrations were independently associated with higher adiponectin levels, particularly when BMI was high. Dietary sodium balance and circulating RAAS activity did not appear to affect this relationship. Future studies should explore whether vitamin D supplementation increases adiponectin levels in obesity.
\end{abstract}

European Journal of Endocrinology 164 995-1002

\section{Introduction}

Adiponectin is a peptide hormone secreted almost exclusively by adipose tissue, yet paradoxically obesity is a state of hypoadiponectinemia $(1,2)$. Because higher adiponectin concentrations are associated with improved cardiovascular profiles, identifying etiologies for adiponectin deficiency and methods to raise circulating adiponectin in obesity may have clinical importance (1, 3-6).

In addition to adiponectin deficiency, obesity has consistently been shown to be a condition of relative vitamin D deficiency $(7,8)$ and excess tissue reninangiotensin-aldosterone system (RAAS) activity (9-13); adipocytes produce all of the components of the RAAS, generating a local adipose tissue RAAS that is distinctly regulated from the circulating RAAS (12-18). This may be relevant since increased RAAS activity lowers adiponectin, while inhibiting the RAAS increases it (19-24); whether increased adipose tissue RAAS activity in obesity contributes to adiponectin deficiency is not known. Prior cross-sectional studies suggested a positive association between 25-hydroxyvitamin D (25(OH)D) and adiponectin; however, they were not designed to study the role of the RAAS in this relationship (25-27). As age, gender, race, body mass index (BMI), hypertension status, dietary sodium balance, and RAAS activity are all known to affect adiponectin measurements $(1,22,23$, 28-31), the independent association of vitamin D and 
adiponectin is best evaluated after controlling or adjusting for these elements.

Vitamin D is an inhibitor of renin expression in animals (32-34), and accruing evidence in humans has associated vitamin D deficiency with augmented RAAS activity, particularly in obesity (11, 35-38). Recent evidence suggests that the association between metabolic disturbances and both $25(\mathrm{OH}) \mathrm{D}$ and adiponectin strengthens with obesity, where adipose tissue RAAS activity is high $(7,12,39)$. Thus, one explanation for these previously observed findings (25-27) is that higher vitamin D levels increase adiponectin levels by lowering adipose tissue RAAS activity.

We evaluated whether $25(\mathrm{OH}) \mathrm{D}$ concentrations were positively associated with circulating adiponectin, using a study design that meticulously controlled and adjusted for age, gender, race, hypertension status, and circulating RAAS activity in a Clinical Research Center (CRC). As increased adiposity is a known modifier of relationships involving vitamin $\mathrm{D}$ and adiponectin $(7,39)$, we also evaluated whether BMI was an effect modifier of the relationship between $25(\mathrm{OH}) \mathrm{D}$ and circulating adiponectin. We hypothesized that if BMI modified the relationship between 25(OH)D and adiponectin, this could indirectly implicate the adipose tissue RAAS as a potential mediator for this association, because its activity burden increases with higher adiposity states $(13,40)$.

\section{Methods and procedures}

\section{Study population}

This cross-sectional analysis was performed on the data gathered from subjects studied in the International Hypertensive Pathotype (HyperPATH) Consortium. The HyperPATH study is an on going, multi-site study aimed at investigating the pathophysiologic and genotypic mechanisms involved in hypertension and cardiovascular diseases. The participants were studied under one common protocol (see below) at four collaborating centers: Brigham and Women's Hospital (Boston, MA, USA), University of Utah Medical Center (Salt Lake City, UT, USA), Vanderbilt University Hospital (Nashville, TN, USA), and Hôpital European Georges Pompidou (Paris, France). All samples obtained were sent to a central laboratory for analysis (Brigham and Women's Hospital).

Subjects with chronic kidney disease, coronary heart disease, heart failure, suggested or known causes of secondary hypertension, and active malignancy were not enrolled in the original HyperPATH study. The enrolled subjects were classified as having hypertension if they had an untreated seated diastolic blood pressure (DBP) $>100 \mathrm{mmHg}$, a DBP $>90 \mathrm{mmHg}$ with one or more antihypertensive medications, measured as the average of three readings with standard manual sphygmomanometer, or the use of two or more antihypertensive medications. Study procedures included dietary sodium modulation to maintain high dietary sodium (HS) and low dietary sodium balance (LS) in sequence.

Following the original study, 25(OH)D measurements were performed on all available frozen plasma of subjects with hypertension $(n=345)$. As gender, race, and hypertension status may all influence adiponectin concentrations (28-31) and RAAS physiology (41-43), we restricted the current cross-sectional analysis to Caucasian men with $25(\mathrm{OH}) \mathrm{D}$ measurements classified as having hypertension and successfully maintained in sodium balance per study protocols (below) and used their available frozen plasma to measure total adiponectin concentrations to comprise the final study population $(n=115)$.

\section{The HyperPATH study protocol}

The HyperPATH study design uses a rigorous study protocol, conducted in CRCs, designed to minimize modifiable confounders of the circulating RAAS (dietary sodium intake, body posture, diurnal variation, and medications). Measurement of the adipose tissue RAAS was not undertaken in the HyperPATH study; however, the adipose tissue RAAS has been shown to function autonomously from the circulating RAAS and is not regulated by the traditional feedback from volume and sodium balance (44). To avoid interference with circulating RAAS assessment, participants taking angiotensin converting enzyme inhibitors, angiotensin receptor blockers, or mineralocorticoid receptor antagonists, were withdrawn from these medications 3 months before study initiation. $\beta$-Blockers were withdrawn 1 month before study initiation. If needed for blood pressure control, subjects were treated with amlodipine and/or hydrochlorothiazide; however, these medications were stopped 3 weeks prior to laboratory evaluation.

Subjects were sequentially maintained in LS $(\leq 10 \mathrm{mmol} / 24 \mathrm{~h})$ and then in HS $(\geq 200 \mathrm{mmol} /$ $24 \mathrm{~h}$ ) for 5-7 days each, using diets provided by the CRC metabolic kitchen. Both study diets also included fixed quantities of potassium $(80 \mathrm{mmol} /$ day $)$ and calcium (1000 mg/day). Study diets were not controlled for macronutrient or calorie intake. After completion of each diet phase, participants were admitted to the institutional CRC and maintained in a supine position overnight. External sodium balance and diet compliance were confirmed on admission to the CRC with a $24 \mathrm{~h}$ urine sodium excretion of $\geq 150 \mathrm{mmol}$ for HS and $\leq 30 \mathrm{mmol}$ for LS. For each diet phase, on the morning following admission, baseline blood sampling was obtained after overnight supine rest, collected on ice and centrifuged immediately for $20 \mathrm{~min}$, and plasma separated and frozen without preservatives until assayed. Blood samples were processed at a central 
laboratory (Brigham and Women's Hospital). Baseline blood pressure was determined while supine, following $10 \mathrm{~h}$ of overnight rest using the average of five readings from a Dinamap automated device (Critikon, Tampa, FL, USA). Study protocols were approved by the Human Subjects Committees/Institutional Review Boards of each location, and informed written consent was obtained from each subject.

\section{Biochemical assessments}

All 115 subjects had a single plasma 25(OH)D level measured at baseline on the first day of the study (Diasorin, Inc., Stillwater, MN, USA; intra-assay variation $4.4-8.3 \%$, inter-assay variation $6.2-12.5 \%$ ). Circulating RAAS activity was assessed via plasma renin activity (PRA) (Diasorin, Inc.; intra-assay variation $4.6-10 \%$, inter-assay variation $5.6-7.6 \%$ ) using previously described methods with a lower limit of detection of $0.10 \mathrm{ng} / \mathrm{ml}$ per $\mathrm{h}$ (45), and serum aldosterone (Siemens, Los Angeles, CA, USA; intraassay variation $2.5-5.4 \%$, inter-assay variation $3.8-15.7 \%$ ) measured from the morning baseline blood sampling of both HS and LS phases. Plasma total adiponectin (ALPCO Diagnostics, Inc., Salem, NH, USA; intra-assay variation $5.0-5.4 \%$, inter-assay variation 6\%), plasma glucose, and insulin were also measured from these blood samples. The homeostasis model assessment index (HOMA-IR) was calculated from plasma glucose and insulin values ((glucose) $\times$ (insulin)/405) (46) and used in multivariable analyses as a general representation of insulin resistance.

\section{Statistical methods}

Sequential analyses were performed to evaluate i) the effect of dietary sodium/RAAS modulation on circulating adiponectin, ii) the association of BMI with adiponectin on each diet, iii) the association of 25(OH)D with adiponectin on each diet, and iv) whether BMI modified the relationship between $25(\mathrm{OH}) \mathrm{D}$ and adiponectin on each diet.

Paired $t$-tests were used to compare the demographic data between HS and LS for normally distributed variables, which are presented as mean values with S.D. Non-normally distributed variables (adiponectin, HOMA-IR, PRA, and aldosterone) are presented with median values and interquartile ranges and compared using the non-parametric Wilcoxon ranks test when paired. BMI was categorized based on the clinically relevant definitions (lean: <25; overweight: 25-29.9; obese: $\left.\geq 30 \mathrm{~kg} / \mathrm{m}^{2}\right)(47)$. One-way analyses of variance were used to compare means between BMI categories.

Multivariable linear regression, with adjustment for age, BMI, and HOMA-IR, was employed to test all continuous associations with adiponectin. These covariates were chosen for their clinical relevance and univariate associations with adiponectin. Linear regression results are reported with effect estimates $(\beta)$, the 95\% confidence intervals for $\beta$, and the corresponding $P$ value. Non-normally distributed variables were transformed to their natural logarithm when used in linear regression models (adiponectin, PRA, aldosterone, and HOMA-IR). To evaluate whether BMI was a statistically significant effect modifier of the relationship between $25(\mathrm{OH}) \mathrm{D}$ and adiponectin, two multivariable interaction models were used. BMI was used as a categorical variable in the first interaction model and as a continuous variable in the second for concordance. These interaction models included age, 25(OH)D, BMI, HOMA-IR, and an interaction term between BMI and 25(OH)D. To account for a multiple testing, a Bonferroni-adjusted $P$ value of 0.025 for significance was applied to these two interaction models. The level for significance for all other tests conducted was set at $\alpha=0.05$, with all reported $P$ values as two tailed. Data analyses were performed using SAS statistical software, v9.1 (Cary, NC, USA).

\section{Results}

\section{Population characteristics}

The mean age of the study population was 48.4 years old (s.D. $=7.7$, range 25-66). They were overweight with a mean BMI of $27.9 \mathrm{~kg} / \mathrm{m}^{2}$ (S.D. $=3.3$, range $20.3-$ $35.3)$ and had a mean $25(\mathrm{OH}) \mathrm{D}$ concentration of $22.6 \mathrm{ng} / \mathrm{ml}$ (s.D. $=8.8$, range 7.3-58.0), consistent with vitamin $\mathrm{D}$ insufficiency by current clinical consensus (48). As anticipated, HS balance resulted in increased blood pressure, suppression of circulating RAAS activity, and lower HOMA-IR, when compared with LS balance (49-51) (Table 1). Consistent with previous observations in lean normotensive men $(22,23)$, adiponectin concentrations in this population of overweight hypertensive men were significantly higher in HS balance where circulating RAAS activity was suppressed, when compared with LS balance where RAAS activity was high (Table 1). Mean 25(OH)D

Table 1 Study population characteristics in LS and HS balance. Results reported as mean (s.D.) for normally distributed variables and median (interquartile range) for non-normally distributed variables.

\begin{tabular}{lccc}
\hline & LS & HS & $\boldsymbol{P}$ \\
\hline 24 h urine sodium & $13.5(7.6)$ & $238.2(64.4)$ & $<0.0001$ \\
$\quad(\mathrm{mmol})$ & & & \\
Systolic BP $(\mathrm{mmHg})$ & $132.2(18.1)$ & $143.7(18.8)$ & $<0.0001$ \\
Diastolic BP $(\mathrm{mmHg})$ & $79.3(11.1)$ & $88.1(11.8)$ & $<0.0001$ \\
HOMA-IR & $2.4(1.7,3.6)$ & $2.0(1.4,3.1)$ & 0.001 \\
Adiponectin $(\mu \mathrm{g} / \mathrm{ml})$ & $2.4(1.8,3.4)$ & $2.9(2.3,4.1)$ & $<0.0001$ \\
PRA $(\mathrm{ng} / \mathrm{ml} \mathrm{per} \mathrm{h})$ & $3.7(1.1,4.5)$ & $0.50(0.26,0.90)$ & $<0.0001$ \\
Aldosterone $(\mathrm{ng} / \mathrm{dl})$ & $16.7(12.2,24.8)$ & $4.1(2.7,7.0)$ & $<0.0001$
\end{tabular}

LS, low dietary sodium; HS, high dietary sodium. 
concentrations expectedly declined with increasing categories of BMI $(7,8)(27.4 \pm 11.8,22.4 \pm 7.6$, and $20.4 \pm 7.7 \mathrm{ng} / \mathrm{ml}$ for lean, overweight, and obese individuals respectively; $P=0.01$ ).

\section{Adiponectin and BMI}

The continuous association between BMI and adiponectin, which is known to be an inverse relationship (3), was analyzed on each study diet to evaluate the influence of the circulating RAAS on this relationship. In LS balance where circulating RAAS activity was high, higher BMI was associated with lower circulating adiponectin (univariate $\beta=-0.034(-0.05,-0.01)$, $P<0.01)$, even after multivariable adjustments (adjusted $\beta=-0.025(-0.048,-0.001), P=0.03)$. Similarly, in HS balance where RAAS activity was suppressed, this relationship paralleled the inverse relationship seen in LS, but as expected, with higher adiponectin concentrations for all values of BMI both before (univariate $\beta=-0.038$ ( -0.06 , $-0.02), P<0.001)$ and after multivariable adjustments (adjusted $\beta=-0.027(-0.050,-0.004)$, $P=0.02$; Fig. 1).

As circulating RAAS activity was inversely associated with adiponectin (Table 1), but the relationship between BMI and adiponectin appeared to be independent of circulating RAAS activity or dietary sodium balance, we examined components of circulating RAAS activity as a function of BMI. In the context of our dietary conditions, BMI was not associated with either PRA or serum aldosterone (Table 2).

\section{Adiponectin and 25(OH)D}

The association between $25(\mathrm{OH}) \mathrm{D}$ and adiponectin was evaluated under each dietary condition. A positive

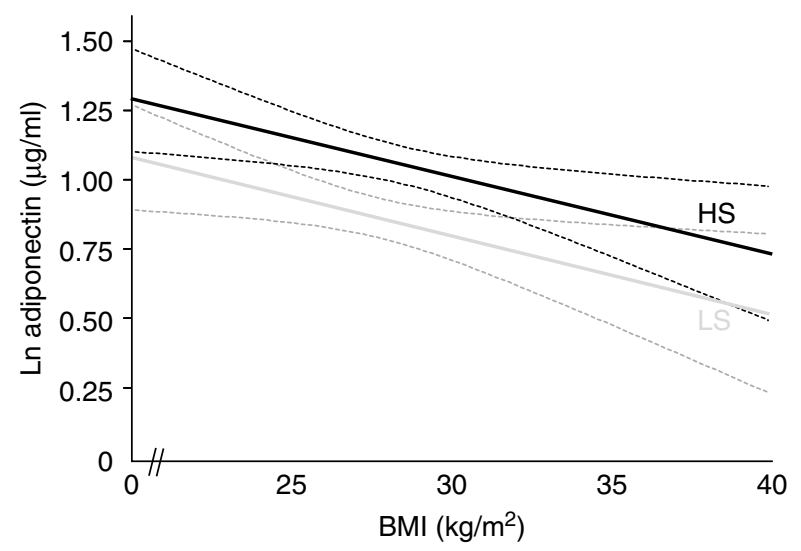

Figure 1 The univariate relationships between BMI and adiponectin plotted in LS (gray) and HS (black) balance, with 95\% confidence intervals for each regression line (For LS balance: univariate $\beta=-0.034(-0.05,-0.01), P<0.01$; for HS balance: univariate $\beta=-0.038(-0.06,-0.02), P<0.001)$. relationship between $25(\mathrm{OH}) \mathrm{D}$ and adiponectin was observed in LS balance (univariate $\beta=0.011$ (0.002, 0.019), $P=0.01)$ that remained significant after multivariable adjustments (adjusted $\beta=0.009$ (0.001, $0.018), P=0.03)$. Although the graphical relationship between $25(\mathrm{OH}) \mathrm{D}$ and adiponectin concentrations in HS appeared to parallel that seen in LS (Fig. 2), this trend was not statistically significant (univariate $\beta=0.007$ ( $-0.001,0.016), P=0.08$ ) (Fig. 2).

\section{BMI influences the relationship between adiponectin and $25(\mathrm{OH}) \mathrm{D}$}

The relationship between $25(\mathrm{OH}) \mathrm{D}$ and adiponectin was evaluated as a function of BMI and was observed to strengthen with increasing BMI status, with maximal magnitude and significance in the obese subgroup (Table 3). We employed adjusted interaction models to assess whether BMI was a statistically significant effect modifier of the relationship between 25(OH)D and adiponectin and observed that the positive association between $25(\mathrm{OH}) \mathrm{D}$ and adiponectin strengthened with increasing BMI categories (LS: $P$ interaction < 0.01 ; HS: $P$ interaction $<0.01)$; higher $25(\mathrm{OH}) \mathrm{D}$ concentrations were associated with higher circulating adiponectin with progression to obesity. The association between $25(\mathrm{OH}) \mathrm{D}$ and adiponectin also strengthened with increasing BMI as a continuous measure in LS ( $P$ interaction $<0.01$ ) but was marginally non-significant in HS $(P$ interaction $=0.06)$.

\section{Discussion}

The relationship between vitamin $\mathrm{D}$, adiponectin, the RAAS, and obesity is complex and intertwined. We evaluated whether the positive association between $25(\mathrm{OH}) \mathrm{D}$ and adiponectin was independent of circulating RAAS activity and also hypothesized that this association would strengthen with increasing BMI. The latter hypothesis could indirectly support a mechanism of vitamin D-mediated lowering of the adipose tissue RAAS resulting in higher circulating adiponectin concentrations.

We observed several notable findings in this analysis. First, we found that in Caucasian hypertensive men who were generally overweight, total adiponectin was inversely related to circulating RAAS activity when modulated by dietary sodium intake. We also observed that adiponectin was inversely associated with BMI and positively associated with $25(\mathrm{OH}) \mathrm{D}$ regardless of dietary sodium intake and circulating RAAS activity (known modulators of circulating adiponectin $(22,23))$. Finally, the association between $25(\mathrm{OH}) \mathrm{D}$ and adiponectin strengthened with increasing BMI and was only significant among obese individuals, where the burden of adipose tissue RAAS activity is expected to be higher $(12,13,40)$. 
Table 2 Circulating components of the RAAS are not associated with BMI. Results reported as the univariate effect estimates for the relationship between BMI and plasma renin activity or aldosterone in LS and HS balance.

\begin{tabular}{cccccccc}
\hline & \multicolumn{3}{c}{ LS } & & \multicolumn{3}{c}{ HS } \\
\cline { 2 - 3 } \cline { 6 - 7 } & $\beta$ & $95 \% \mathrm{Cl}$ & $P$ & & $\beta$ & $95 \% \mathrm{Cl}$ & $P$ \\
\hline PRA & 0.02 & -0.04, & 0.59 & & -0.03 & -0.08, & 0.26 \\
(ng/ml/h) & & 0.07 & & & 0.02 & \\
Aldosterone & -0.003 & -0.03, & 0.84 & & -0.004 & -0.04, & 0.82 \\
(ng/dl) & & 0.03 & & & 0.03 & \\
\hline
\end{tabular}

$\beta$, effect estimate; $\mathrm{Cl}$, confidence interval.

As obesity is a state of hypoadiponectinemia $(7,8)$ and relative vitamin $\mathrm{D}$ deficiency $(1,2)$, the clinical importance of our cross-sectional observations is providing data to suggest that vitamin D supplementation may raise adiponectin levels in obesity, an outcome which is associated with lower cardiovascular risk (3-6). The mechanistic implications of our observations may be understood in the context of prior studies that have shown increased local tissue RAAS activity in obesity $(13,15,17,40,52)$, reduction of adiponectin concentrations with increased RAAS activity (19-24), and an inverse relationship between vitamin D and RAAS activity $(11,35-38)$. We speculate that our findings may indirectly support the adipose tissue RAAS as an important negative paracrine regulator of adiponectin secretion in adipose tissue (21); the adipose tissue RAAS may in turn may be negatively regulated by vitamin $\mathrm{D}(10,11,35,36,38)$. With this hypothesized mechanism, vitamin D supplementation could raise circulating adiponectin in obesity by downregulating adipose tissue RAAS activity. As our cross-sectional study did not include direct measurements of the adipose tissue RAAS, it was not designed to make conclusions about the specific role adipose tissue RAAS may play but rather may generate novel

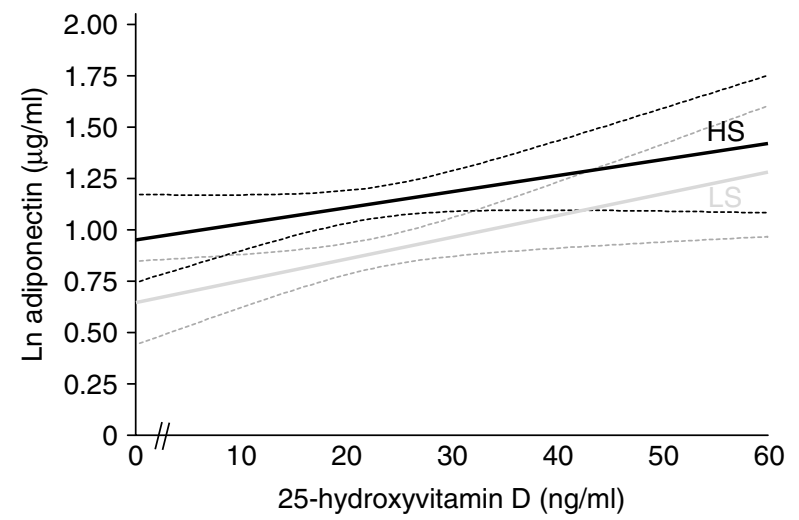

Figure 2 The univariate relationships between 25(OH)D and adiponectin plotted in LS (gray) and HS (black) balance, with 95\% confidence intervals for each regression line (For LS balance: univariate $\beta=0.011(0.002,0.019), P=0.01$; for HS balance: univariate $\beta=0.007(-0.001,0.016), P=0.08)$. hypotheses regarding the mechanism for our associations.

Our findings are consistent with and extend the work of others. Prior investigations have demonstrated reciprocal changes in adiponectin when modulating the circulating RAAS with dietary sodium in a population of lean and healthy normotensive men $(22,23)$. Similarly, we also observed a decrease in adiponectin with increased circulating RAAS activity but in a cohort of largely overweight and hypertensive men with comparatively unfavorable metabolic profiles and lower adiponectin concentrations; raising adiponectin in this population may improve cardiovascular risk (4), while hypoadiponectinemia may worsen it $(5,6)$.

As expected, we observed that adiponectin concentrations declined with increasing BMI (3). The strength of association between BMI and adiponectin concentrations was the same irrespective of sodium balance (LS or HS) or circulating RAAS activity, suggesting that the inverse relationship between adiponectin and adiposity may be independent of circulating RAAS activity. We observed no association between BMI and individual circulating RAAS components; in contrast, an inverse association between circulating and adipose tissue RAAS activity with adiponectin is well established (19-24). This raised the possibility that higher local RAAS activity within the adipose tissue compartment could exert important local or paracrine influences that determine the lower adiponectin concentrations with obesity. The adipose tissue RAAS is not influenced by the traditional sodium homeostasis and blood pressure feedback mechanisms (44) and has been shown to modulate adiponectin concentrations in transgenic mice (21). In these animal models, mice lacking the angiotensinogen gene exhibited higher adiponectin concentrations when compared with wild-type mice; however, in knockout mice who expressed angiotensinogen only in adipose tissue, adiponectin declined back to wild-type levels.

We postulated that understanding the relationship between vitamin $\mathrm{D}$ and adiponectin may provide further insight into the hypothesized role the adipose tissue RAAS plays in regulating adiponectin in obesity. Vitamin D metabolites have been shown to exhibit an inverse relationship with renin as well as local tissue RAAS activity, implicating vitamin $\mathrm{D}$ as an endogenous antagonist of the RAAS by inhibiting renin expression $(10,11,33,35-38,53)$. Furthermore, vitamin D status is intertwined with the obesity epidemic in that higher adiposity is associated with vitamin D deficiency (8).

Assimilating these prior observations, we hypothesized that 25(OH)D deficiency could explain the augmented adipose tissue RAAS activity and resultant changes in adiponectin concentrations in obesity. Since activity of the adipose tissue RAAS increases with progressive adiposity (12), we speculated that the association between $25(\mathrm{OH}) \mathrm{D}$ and adiponectin 
Table 3 The association between 25-hydroxyvitamin D (25(OH)D) and adiponectin strengthens with increasing adiposity (Lean: BMI $<25 \mathrm{~kg} / \mathrm{m}^{2}$; Overweight: BMI $25-29.9 \mathrm{~kg} / \mathrm{m}^{2}$; Obese: BMI $\left.\geq 30 \mathrm{~kg} / \mathrm{m}^{2}\right)$. The association between $25(\mathrm{OH}) \mathrm{D}$ and adiponectin stratified by body mass index status in LS and HS balance, reported as unadjusted effect estimates $(\beta)$ and $95 \%$ confidence intervals for $\beta$ with $P$ values $(P)$.

\begin{tabular}{llll}
\hline & $\begin{array}{l}\text { Lean } \\
(n=20)\end{array}$ & $\begin{array}{l}\text { Overweight } \\
(n=59)\end{array}$ & $\begin{array}{l}\text { Obese } \\
(n=36)\end{array}$ \\
\hline LS & & & \\
$\beta$ & -0.012 & 0.011 & 0.024 \\
$95 \% \mathrm{Cl}$ & $-0.027,0.003$ & $-0.001,0.023$ & $\begin{array}{l}0.007,0.041 \\
P\end{array}$ \\
\hline HS & 0.12 & 0.07 & $<0.01$ \\
$\beta$ & & & \\
$95 \% \mathrm{Cl}$ & -0.006 & 0.002 & 0.016 \\
$P$ & $-0.025,0.012$ & $-0.011,0.016$ & $0.0001,0.032$ \\
\hline
\end{tabular}

would strengthen with increasing BMI. With higher BMI, we observed that the strength of the positive association between 25(OH)D and adiponectin increased and became significant; BMI was a statistically significant effect modifier of this relationship. Specifically, we observed that 25(OH)D and adiponectin were significantly associated in the obese subgroup; however, it remains to be determined whether this relationship is dependent on obesity per se, the volumes of subcutaneous versus visceral adiposity, or other contributory factors. This observation is consistent with recent reports that have implicated adiposity as an important modulator of associations concerning 25(OH)D and adiponectin $(7,39)$. Because obese individuals tend to have lower 25(OH)D levels and higher cardiovascular co-morbidities, this finding may bear significant clinical value: the supplementation of vitamin $\mathrm{D}$, which is implicated as a negative biologic regulator of the RAAS (10), may lower adipose tissue RAAS activity and improve adiponectin concentrations, especially in obese individuals.

Our results must be interpreted within the context of our study design. This analysis was cross-sectional and thus cannot prove causality or directionality of associations; prospective vitamin D supplementation studies are required to evaluate the effect on circulating adiponectin. Though our study describes notable associations between $25(\mathrm{OH}) \mathrm{D}$, BMI, and adiponectin, we had no direct measures of the adipose tissue RAAS (which we speculate may play a role in explaining our findings) and acknowledge that several other unmeasured factors that interact with RAAS activity may be involved (sympathetic nervous system, natriuretic peptide system, vasopressin, etc.). Future in vivo or in vitro studies with direct measurements of the adipose tissue RAAS are needed to confirm the mechanistic implications of our associations. Parathyroid hormone has been associated with the RAAS (54); however, whether its role is independent of vitamin D metabolites remains unresolved. Our study design controlled for dietary sodium and calcium intake, but we did not have parathyroid hormone, ionized calcium, or $1,25(\mathrm{OH}) \mathrm{D}$ measurements and thus cannot comment on whether our observed associations were independent of these factors. Though the time of the year and seasonality are known to influence 25(OH)D levels (48), our analysis was focused on evaluating the physiologic effect of $25(\mathrm{OH}) \mathrm{D}$ concentrations on adiponectin at the time of study; therefore, we did not adjust for these factors. This analysis consisted of only 115 individuals and thus may not have been adequately powered to detect some trends that fell short of statistical significance; however, our observations are consistently linked to those that have previously described adipose tissue RAAS physiology and regulation $(9,13,52)$ and the relationship between vitamin D and the RAAS (35-38). We studied a population of male Caucasians with hypertension; thus, the generalizability of our results to other races, female gender, and blood pressure status is still uncertain. On the other hand, a major strength of our study was that subjects underwent a paired intervention design with meticulous control for gender, race, sodium/RAAS status, and hypertension phenotype, all of which can confound measures of the RAAS and adiponectin and result in unreliable observations $(22$, $23,28,30,31$ ).

Adipose tissue is an endocrine organ that produces adiponectin and a local tissue RAAS; with progression to obesity, activity of the adipose tissue RAAS increases and adiponectin concentrations decrease. Though adiponectin concentrations are known to decline with higher RAAS activity and higher BMI, we observed that the inverse association between BMI and adiponectin was independent of circulating RAAS activity. Furthermore, $25(\mathrm{OH}) \mathrm{D}$ was positively associated with adiponectin, especially in obesity, and this relationship appeared to be independent of circulating RAAS activity. As $25(\mathrm{OH}) \mathrm{D}$ deficiency is especially prevalent in obesity, future studies to evaluate the relationship between vitamin $\mathrm{D}$ supplementation and adiponectin, as well as the role of the adipose tissue RAAS in this relation, are warranted.

\section{Declaration of interest}

The authors declare that there is no conflict of interest that could be perceived as prejudicing the impartiality of the research reported.

\section{Funding}

F32 HL104776-01 (A Vaidya), F31 NR011108-01 (P C Underwood), K08 HL079929 (J P Forman), KL2 RR025757 (L H Pojoga), SDG 0735609T (L H Pojoga), K23 HL08236-03 (J S Williams), and U54LM008748 from the National Library of Medicine and UL1 RR025758, Harvard Clinical and Translational Science Center, from the National Center for Research Resources and M01-RR02635, Brigham and Women's Hospital, General Clinical Research Center, from the National Center for Research Resources, and the Specialized Center of Research (SCOR) in Molecular Genetics of Hypertension 
P50HL055000. The content is solely the responsibility of the authors and does not necessarily represent the official views of the National Library of Medicine, the National Institutes of Health, or the National Center for Research Resources.

\section{Acknowledgements}

We would like to thank the staff of the Clinical Research Centers at our collaborating institutions, including the Brigham and Women's Hospital, the Centre Investigation Clinique, Hôpital Européen Georges Pompidou, the University of Utah Medical Center, and Vanderbilt University Hospital.

\section{References}

1 Brochu-Gaudreau K, Rehfeldt C, Blouin R, Bordignon V Murphy BD \& Palin MF. Adiponectin action from head to toe. Endocrine 201037 11-32. (doi:10.1007/s12020-009-9278-8)

2 Kershaw EE \& Flier JS. Adipose tissue as an endocrine organ. Journal of Clinical Endocrinology and Metabolism $2004 \mathbf{8 9}$ 2548-2556. (doi:10.1210/jc.2004-0395)

3 Matsuzawa Y. Adiponectin: a key player in obesity related disorders. Current Pharmaceutical Design 201016 1896-1901. (doi:10.2174/138161210791208893)

4 Ohashi K, Kihara S, Ouchi N, Kumada M, Fujita K, Hiuge A. Hibuse T, Ryo M, Nishizawa H, Maeda N, Maeda K, Shibata R, Walsh K, Funahashi T \& Shimomura I. Adiponectin replenishment ameliorates obesity-related hypertension. Hypertension $2006 \mathbf{4 7}$ 1108-1116. (doi:10.1161/01.HYP.0000222368.43759.a1)

5 Gustafsson S, Lind L, Soderberg S \& Ingelsson E. Associations of circulating adiponectin with measures of vascular function and morphology. Journal of Clinical Endocrinology and Metabolism 2010 95 2927-2934. (doi:10.1210/jc.2009-2685)

6 Persson J, Lindberg K, Gustafsson TP, Eriksson P, Paulsson-Berne G \& Lundman P. Low plasma adiponectin concentration is associated with myocardial infarction in young individuals. Journal of Internal Medicine 2010268 194-205. (doi:10.1111/j.1365-2796.2010. 02247.x)

7 Beydoun MA, Boueiz A, Shroff MR, Beydoun HA, Wang Y \& Zonderman AB. Associations among 25-hydroxyvitamin D, diet quality, and metabolic disturbance differ by adiposity in United States adults. Journal of Clinical Endocrinology and Metabolism 2010 95 3814-3827. (doi:10.1210/jc.2010-0410)

8 Snijder MB, van Dam RM, Visser M, Deeg DJ, Dekker JM, Bouter LM, Seidell JC \& Lips P. Adiposity in relation to vitamin D status and parathyroid hormone levels: a population-based study in older men and women. Journal of Clinical Endocrinology and Metabolism 200590 4119-4123. (doi:10.1210/jc.2005-0216)

9 Luft F. The renin, angiotensin, aldosterone, and obesity connection. Journal of Molecular Medicine $2010 \mathbf{8 8} 861-864$. (doi:10. 1007/s00109-010-0664-8)

10 Vaidya A \& Forman JP. Vitamin D and hypertension: current evidence and future directions. Hypertension 201056 774-779. (doi:10.1161/HYPERTENSIONAHA.109.140160)

11 Vaidya A, Forman JP \& Williams JS. Vitamin D and the vascular sensitivity to angiotensin II in obese Caucasians with hypertension. Journal of Human Hypertension, 2010. (doi:10.1038/jhh. 2010.110)

12 Yvan-Charvet L \& Quignard-Boulange A. Role of adipose tissue renin-angiotensin system in metabolic and inflammatory diseases associated with obesity. Kidney International, 2010. (doi:10.1038/ ki.2010)

13 Engeli S, Negrel R \& Sharma AM. Physiology and pathophysiology of the adipose tissue renin-angiotensin system. Hypertension 2000 $351270-1277$.
14 Bader M. Tissue renin-angiotensin-aldosterone systems: targets for pharmacological therapy. Annual Review of Pharmacology and Toxicology 201050 439-465. (doi:10.1146/annurev.pharmtox. 010909.105610)

15 Faloia E, Gatti C, Camilloni MA, Mariniello B, Sardu C, Garrapa GG, Mantero F \& Giacchetti G. Comparison of circulating and local adipose tissue renin-angiotensin system in normotensive and hypertensive obese subjects. Journal of Endocrinological Investigation 200225 309-314.

16 Reudelhuber TL. Deciphering the roles of tissue renin-angiotensin systems in whole animals. Hypertension $2010 \quad 57$ 532-537. (doi:10.1161/HYPERTENSIONAHA.110.167114)

17 Sarzani R, Salvi F, Dessi-Fulgheri P \& Rappelli A. Reninangiotensin system, natriuretic peptides, obesity, metabolic syndrome, and hypertension: an integrated view in humans. Journal of Hypertension 200826 831-843. (doi:10.1097/HJH. Ob013e3282f624a0)

18 Briones AMCA, Callera GE, Yogi A, Burger D, He Y, Correa JW, Gagnon AM, Gomez-Sanchez C, Gomez-Sanchez E, Sorisky A, Burns K \& Touyz R. Production of aldosterone by adipocytes: implications for obesity and vascular function. Hypertension, 2010 e50-e166.

19 Inoue Y, Kakuma T, Nonaka Y, Sumi S, Okamura K, Kodama S, Ando C, Niimura H, Miyoshi K, Tsuchiya Y, Yamanouchi Y \& Urata H. Beneficial effect of combination therapy comprising angiotensin II receptor blocker plus calcium channel blocker on plasma adiponectin levels. Clinical and Experimental Hypertension 201032 21-28. (doi:10.3109/10641960902960516)

20 Kamari Y, Shimoni N, Koren F, Peleg E, Sharabi Y \& Grossman E. High-salt diet increases plasma adiponectin levels independent of blood pressure in hypertensive rats: the role of the reninangiotensin-aldosterone system. Journal of Hypertension 2010 28 95-101. (doi:10.1097/HJH.0b013e3283325eee)

21 Kim S, Soltani-Bejnood M, Quignard-Boulange A, Massiera F, Teboul M, Ailhaud G, Kim JH, Moustaid-Moussa N \& Voy BH. The adipose renin-angiotensin system modulates systemic markers of insulin sensitivity and activates intrarenal renin-angiotensin system. Journal of Biomedicine and Biotechnology 20062006 1-6. (doi:10.1155/JBB/2006/27012)

22 Krikken JA, Dallinga-Thie GM, Navis G \& Dullaart RP. Short term dietary sodium restriction decreases HDL cholesterol, apolipoprotein A-I and high molecular weight adiponectin in healthy young men: relationships with renal hemodynamics and RAAS activation. Nutrition, Metabolism, and Cardiovascular Diseases, 2010. (doi:10.1016/j.numecd.2010.03.010)

23 Lely AT, Krikken JA, Bakker SJ, Boomsma F, Dullaart RP, Wolffenbuttel BH \& Navis G. Low dietary sodium and exogenous angiotensin II infusion decrease plasma adiponectin concentrations in healthy men. Journal of Clinical Endocrinology and Metabolism 200792 1821-1826. (doi:10.1210/jc.2006-2092)

24 Ran J, Hirano T, Fukui T, Saito K, Kageyama H, Okada K \& Adachi M. Angiotensin II infusion decreases plasma adiponectin level via its type 1 receptor in rats: an implication for hypertension-related insulin resistance. Metabolism $2006 \mathbf{5 5}$ 478-488. (doi:10.1016/j.metabol.2005.10.009)

25 Gannage-Yared MH, Chedid R, Khalife S, Azzi E, Zoghbi F \& Halaby G. Vitamin D in relation to metabolic risk factors, insulin sensitivity and adiponectin in a young Middle-Eastern population. European Journal of Endocrinology 2009160 965-971. (doi:10. 1530/EJE-08-0952)

26 Liu E, Meigs JB, Pittas AG, McKeown NM, Economos CD, Booth SL \& Jacques PF. Plasma 25-hydroxyvitamin D is associated with markers of the insulin resistant phenotype in nondiabetic adults. Journal of Nutrition 2009139 329-334. (doi:10.3945/jn.108. 093831)

27 Nimitphong H, Chanprasertyothin S, Jongjaroenprasert $W$ \& Ongphiphadhanakul B. The association between vitamin D status and circulating adiponectin independent of adiposity in subjects with abnormal glucose tolerance. Endocrine 200936 205-210. (doi:10.1007/s12020-009-9216-9) 
28 Smith LM, Yao-Borengasser A, Starks T, Tripputi M, Kern PA \& Rasouli N. Insulin resistance in African-American and Caucasian women: differences in lipotoxicity, adipokines, and gene expression in adipose tissue and muscle. Journal of Clinical Endocrinology and Metabolism 2010 95 4441-4448. (doi:10.1210/jc.2010-0017)

29 Lu G, Chiem A, Anuurad E, Havel PJ, Pearson TA, Ormsby B \& Berglund L. Adiponectin levels are associated with coronary artery disease across Caucasian and African-American ethnicity. Translational Research 2007149 317-323. (doi:10.1016/j.trsl.2006. 12.008)

30 Marques-Vidal P, Bochud M, Paccaud F, Mooser V, Waeber G \& Vollenweider P. Distribution of plasma levels of adiponectin and leptin in an adult Caucasian population. Clinical Endocrinology 201072 38-46. (doi:10.1111/j.1365-2265.2009.03628.x)

31 Celoria BM, Genelhu VA, Pimentel Duarte SF, Delfraro PA \& Francischetti EA. Hypoadiponectinemia is associated with prehypertension in obese individuals of multiethnic origin. Clinical Cardiology 201033 E61-E65. (doi:10.1002/clc.20657)

$32 \mathrm{Li}$ YC. Vitamin D regulation of the renin-angiotensin system. Journal of Cellular Biochemistry 200388 327-331. (doi:10.1002/ jcb.10343)

$33 \mathrm{Li}$ YC, Kong J, Wei M, Chen ZF, Liu SQ \& Cao LP. 1,25Dihydroxyvitamin $\mathrm{D}(3)$ is a negative endocrine regulator of the renin-angiotensin system. Journal of Clinical Investigation 2002 110 229-238. (doi:10.1172/JCI200215219)

34 Yuan W, Pan W, Kong J, Zheng W, Szeto FL, Wong KE, Cohen R, Klopot A, Zhang Z \& Li YC. 1,25-Dihydroxyvitamin $\mathrm{D}_{3}$ suppresses renin gene transcription by blocking the activity of the cyclic AMP response element in the renin gene promoter. Journal of Biological Chemistry 2007 282 29821-29830. (doi:10.1074/jbc. M705495200)

35 Resnick LM, Muller FB \& Laragh JH. Calcium-regulating hormones in essential hypertension. Relation to plasma renin activity and sodium metabolism. Annals of Internal Medicine 1986 105 649-654.

36 Tomaschitz A, Pilz S, Ritz E, Grammer T, Drechsler C, Boehm BO \& Marz W. Independent association between 1,25-dihydroxyvitamin D, 25-hydroxyvitamin D and the renin-angiotensin system: the Ludwigshafen Risk and Cardiovascular Health (LURIC) Study. Clinical Chemica Acta 2010411 1354-1360. (doi:10.1016/j.cca. 2010.05.037)

37 Forman JP, Williams JS \& Fisher ND. Plasma 25-hydroxyvitamin D and regulation of the renin-angiotensin system in humans. Hypertension 2010 55 1283-1288. (doi:10.1161/HYPERTENSIONAHA.109.148619)

38 Vaidya A, Forman JP \& Williams JS. 25-Hydroxyvitamin D is associated with plasma renin activity and the pressor response to dietary sodium intake in Caucasians. Journal of the Renin-Angiotensin-Aldosterone System, 2010. (doi:10.1177/ 1470320310391922 )

39 Martin LJ, Woo JG, Daniels SR, Goodman E \& Dolan LM. The relationships of adiponectin with insulin and lipids are strengthened with increasing adiposity. Journal of Clinical Endocrinology and Metabolism 200590 4255-4259. (doi:10.1210/jc.2005-0019)

40 Yasue S, Masuzaki H, Okada S, Ishii T, Kozuka C, Tanaka T, Fujikura J, Ebihara K, Hosoda K, Katsurada A, Ohashi N, Urushihara M, Kobori H, Morimoto N, Kawazoe T, Naitoh M, Okada M, Sakaue H, Suzuki S \& Nakao K. Adipose tissue-specific regulation of angiotensinogen in obese humans and mice: impact of nutritional status and adipocyte hypertrophy. American Journal of Hypertension $2010 \mathbf{2 3}$ 425-431. (doi:10.1038/ajh. 2009.263)
41 Price DA, Fisher ND, Lansang MC, Stevanovic R, Williams GH \& Hollenberg NK. Renal perfusion in blacks: alterations caused by insuppressibility of intrarenal renin with salt. Hypertension 2002 40 186-189. (doi:10.1161/01.HYP.0000024349.85680.87)

42 Price DA \& Fisher ND. The renin-angiotensin system in blacks: active, passive, or what? Current Hypertension Reports $2003 \mathbf{5}$ 225-230. (doi:10.1007/s11906-003-0025-x)

43 Forman JP, Price DA, Stevanovic R \& Fisher ND. Racial differences in renal vascular response to angiotensin blockade with captopril or candesartan. Journal of Hypertension 200725 877-882. (doi:10.1097/HJH.0b013e32803caela)

44 Engeli S, Boschmann M, Frings P, Beck L, Janke J, Titze J, Luft F, Heer M \& Jordan J. Influence of salt intake on renin-angiotensin and natriuretic peptide system genes in human adipose tissue. Hypertension $2006 \mathbf{4 8}$ 1103-1108. (doi:10.1161/01.HYP. $0000248837.88749 .18)$

45 Emanuel RL, Cain JP \& Williams GH. Double antibody radioimmunoassay of renin activity and angiotensin II in human peripheral plasma. Journal of Laboratory and Clinical Medicine 1973 81 632-640.

46 Matthews DR, Hosker JP, Rudenski AS, Naylor BA, Treacher DF \& Turner RC. Homeostasis model assessment: insulin resistance and beta-cell function from fasting plasma glucose and insulin concentrations in man. Diabetologia 198528 412-419. (doi:10. 1007/BF00280883)

47 Physical status: the use and interpretation of anthropometry. Report of a WHO Expert Committee. World Health Organization Technical Report Series 1995854 1-452.

48 Holick MF. Vitamin D deficiency. New England Journal of Medicine 2007357 266-281. (doi:10.1056/NEJMra070553)

49 Perry CG, Palmer T, Cleland SJ, Morton IJ, Salt IP, Petrie JR, Gould GW \& Connell JM. Decreased insulin sensitivity during dietary sodium restriction is not mediated by effects of angiotensin II on insulin action. Clinical Science $2003 \mathbf{1 0 5} 187-194$. (doi:10. $1042 /$ CS20020320)

50 Townsend RR, Kapoor S \& McFadden CB. Salt intake and insulin sensitivity in healthy human volunteers. Clinical Science 2007113 141-148. (doi:10.1042/CS20060361)

51 Vaidya A, Pojoga L, Underwood PC, Forman JP, Hopkins PN, Williams GH \& Williams JS. The association of plasma resistin with dietary sodium manipulation, the renin-angiotensin-aldosterone system, and 25-hydroxyvitamin $\mathrm{D}(3)$ in human hypertension. Clinical Endocrinology 201174 294-299. (doi:10.1111/j.13652265.2010.03922.x)

52 Engeli S, Schling P, Gorzelniak K, Boschmann M, Janke J, Ailhaud G, Teboul M, Massiera F \& Sharma AM. The adiposetissue renin-angiotensin-aldosterone system: role in the metabolic syndrome? International Journal of Biochemistry \& Cell Biology 200335 807-825. (doi:10.1016/S1357-2725(02)00311-4)

53 Vaidya A, Sun B, Forman JP, Hopkins PN, Brown NJ, Kolatkar NS, Williams GH \& Williams JS. The vitamin D receptor gene polymorphism Fok1 is associated with plasma renin activity in Caucasians. Clinical Endocrinology, 2011. In press. (doi:10.1111/j. 1365-2265.2011.03991.x)

54 Grant FD, Mandel SJ, Brown EM, Williams GH \& Seely EW. Interrelationships between the renin-angiotensin-aldosterone and calcium homeostatic systems. Journal of Clinical Endocrinology and Metabolism 199275 988-992. (doi:10.1210/jc.75.4.988)

Received 10 February 2011

Accepted 14 March 2011 